\title{
Alphavirus replicon-based enhancement of mucosal and systemic immunity is linked to the innate response generated by primary immunization
}

\author{
Daniel R Tonkin ${ }^{\mathrm{a}}$, Patricia Jorquera ${ }^{\mathrm{a}, \mathrm{c}}$, Tracie Todd ${ }^{\mathrm{a}}$, Clayton W Beard ${ }^{\mathrm{a}}$, Robert E \\ Johnston $^{a, b}$, and Mario Barro ${ }^{a}$ \\ aGlobal Vaccines Inc, Research Triangle Park, NC, 27709, United States \\ ${ }^{b}$ Carolina Vaccine Institute, University of North Carolina, Chapel Hill, NC 27599, United States \\ cUniversidad de Santiago de Chile, Chile
}

\begin{abstract}
Venezuelan equine encephalitis virus replicon particles (VRP) function as an effective systemic, cellular and mucosal adjuvant when codelivered with antigen, and show promise for use as a component in new and existing human vaccine formulations. We show here that VRP are effective at low dose and by intramuscular delivery, two useful features for implementation of VRP as a vaccine adjuvant. In mice receiving a prime and boost with antigen, we found that VRP are required in prime only to produce a full adjuvant effect. This outcome indicates that the events triggered during prime with VRP are sufficient to establish the nature and magnitude of the immune response to a second exposure to antigen. Events induced by VRP in the draining lymph node after prime include robust secretion of many inflammatory cytokines, upregulation of CD69 on leukocytes, and increased cellularity, with a disproportionate increase of a cell population expressing CD11c, CD11b, and F4/80. We show that antigen delivered 24 hours after administration of VRP does not benefit from an adjuvant effect, indicating that the events which are critical to VRP-mediated adjuvant activity occur within the first 24 hours. Further studies of the events induced by VRP will help elucidate the mechanism of VRP adjuvant activity and will advance the safe implementation of this adjuvant in human vaccines.
\end{abstract}

\section{Introduction}

It is a challenge of modern vaccine development to achieve a robust immune response against weakly immunogenic targets such as a subunit vaccines $[1,2]$. Such a result can be achieved by inclusion of an adjuvant, which augments the immune response to codelivered antigen [3] New adjuvants which are safe and potent are needed for the next generation of vaccines. Furthermore, induction of mucosal immunity by an adjuvant should improve protection against pathogens which enter the body by a mucosal route [4,5]. Although mucosal immunity has traditionally been generated in response to a mucosally delivered antigen, it is also possible to generate a mucosal immune response by parenteral delivery of antigen under the right conditions [6-16], including codelivery of replicons from the Venezuelan equine encephalitis

(c) 2010 Elsevier Ltd. All rights reserved.

Publisher's Disclaimer: This is a PDF file of an unedited manuscript that has been accepted for publication. As a service to our customers we are providing this early version of the manuscript. The manuscript will undergo copyediting, typesetting, and review of the resulting proof before it is published in its final citable form. Please note that during the production process errors may be discovered which could affect the content, and all legal disclaimers that apply to the journal pertain. 
virus (VEE) [17]. VEE is a positive sense alphavirus whose RNA genome encodes four nonstructural replicase proteins (nsPs), followed by an internal promoter (26S) which controls the transcription of a subgenomic mRNA encoding the virion structural proteins. The adjuvant qualities of this virus were first identified forty years ago, when it was shown that VEE virus inoculation enhanced the immune response to antigen $[18,19]$. VEE replicon particles (VRP) contain a truncated VEE genome lacking the sequence encoding the structural proteins but retaining the information for the viral replication machinery [20]. Once assembled, VRP are infectious for a first round of replication but cannot further propagate to other cells. While VRP were first developed for their ability to express a foreign immunogen encoded under the control of the $26 \mathrm{~S}$ promoter [20], VRP which encode no foreign genes act as a humoral, cellular and mucosal adjuvant when co-delivered with a soluble antigen [17,21]. VRP can increase protection against norovirus challenge when used as an adjuvant with a murine norovirus subunit vaccine [22]. In non-human primates, codelivery of VRP with a seasonal flu vaccine significantly improved protection upon subsequent homotypic intranasal challenge (C. J. Miller, personal communication). These findings demonstrate the potential for VRP as an adjuvant in human vaccines. Here we attempt to better understand the mechanism by which VRP enhance the immune response.

VRP mediated adjuvant activity most likely involves the activation of an innate immune response, triggered by VRP infection or replication, as evidenced by induction of dendritic cell (DC) maturation and secretion of interferons and other cytokines in response to VRP infection $[23,24]$. In the work reported here, we characterize the efficacy of VRP as an adjuvant in a mouse model and find that VRP are necessary only in the initial priming injection in order to achieve a strong adjuvant effect. We further demonstrate the presence of a rapid inflammatory response triggered by VRP, which is indicative of the activation of innate immunity. A better understanding of these early events after VRP injection should help to determine the pathways which are initiated to produce enhanced systemic, mucosal, and cellular immune responses.

\section{Materials and Methods}

\subsection{VEE Replicon Particles}

Production and packaging of VRP have been previously described [20,25]. Briefly, VRP are packaged into functional particles by electroporation of BHK-21 cells with the replicon genome along with two helper RNAs. The helper RNAs produce the structural proteins in trans but lack the cis-acting packaging sequence, so that only the replicon RNA is incorporated into the viral particles. All replicon particles used in this study were packaged in the wild-type (V3000) envelope [26]. Three VRP genomes were used. VRP-GFP encodes the sequence for GFP under the control of the 26S promoter. VRP16M contains the viral nonstructural genes, $16 \mathrm{nt}$ of VEE sequence downstream of the 26 mRNA transcription start site, an inserted 43-nt multiple cloning site, and the 118-nt 3'UTR. VRP(-5) contains the viral nonstructural genes but is deleted for the region between the nsP4 stop codon ( $5 \mathrm{nts}$ before $26 \mathrm{~S}$ mRNA transcription start site) and the beginning of the 118-nt 3' UTR. Both VRP genomes contain all of the known cisacting signals for RNA replication. The subgenomic mRNA promoter in VRP16M is predicted to program the synthesis of a small, noncoding 3' polyadenylated RNA of $177 \mathrm{nts}$, but VRP $(-5)$ lacks a functional promoter for subgenomic RNA transcription. After purification, the absence of detectable replication-competent virus was confirmed by cytopathic effect assay, and VRP were titered by infection of BHK-21 cells as measured by immunofluorescent staining of VEE non-structural proteins. VRP genome equivalents (GE) were determined by RNA extraction with an Ambion MagMAX Viral RNA Isolation Kit followed by real time PCR using nsP1-specific primers and probe as previously described [27]. The ratio of VRP GE to BHK infectious unit (IU) was approximately $10^{3}$. 


\subsection{Mice and Immunizations}

Six to eight week old female Balb/c or C57B1/6 mice were purchased from Charles River and were housed at the University of North Carolina Division of Laboratory Animal Medicine animal facility according to protocols approved by the Institutional Animal Care and Use Committee. Balb/c mice were used for all experiments except for assay of $\mathrm{T}$ cell responses to OVA, for which C57B1/6 mice were used. Mice were injected in the rear footpad or by intramuscular delivery on week 0 and 4 with chicken egg albumin (OVA) (Sigma) (10 or 100 $\mu \mathrm{g}$ ) alone or OVA mixed with the stated infectious units (IU) of VRP, as described in the text. Endotoxin in the OVA preparation was reduced below the level of detection by phase separation using Triton X-114 [28]. For some experiments, OVA was conjugated to Alexa Fluor 488 using the Alexa Fluor 488 Protein Labeling kit (Invitrogen).

\subsection{Analysis of OVA-specific $\lg G$ and $\lg A$ in serum and fecal extracts}

Serum was collected from mice 3 weeks after boost. For isolation of fecal extracts, fecal pellets were collected 10 days after boost and vortexed at $4{ }^{\circ} \mathrm{C}$ at $0.2 \mathrm{~g} / \mathrm{ml}$ in PBS containing $10 \%$ goat serum and $1 \times$ protease inhibitors (Roche) until pellets were disrupted. Samples were centrifuged, and supernatants were filtered through $0.22 \mu \mathrm{m}$ filters OVA-specific IgG and $\operatorname{IgA}$ antibodies were detected by ELISA on 96-well high binding plates (Thermo Scientific) coated with $10 \mu \mathrm{g} / \mathrm{ml}$ OVA in PBS. Sera and fecal extracts were added to plates in serial dilutions. OVA-specific antibodies were detected with horseradish peroxidase conjugated antibodies specific for mouse IgG (Sigma) or mouse-IgA (Southern Biotechnology) followed by addition of $o$-phenylenediamine dihydrochloride substrate (Sigma) for 30 minutes. Endpoint titers were determined as the last sample dilution that generated an $\mathrm{OD}_{450}$ reading of greater than 0.2 . For determination of total IgA levels in fecal extracts, 96 well plates were coated with $5 \mu \mathrm{g} / \mathrm{ml}$ rabbit anti-mouse IgA (Invitrogen), ELISAs performed as above, and a standard curve generated from dilutions of purified murine $\operatorname{IgA}$ (Sigma). This standard curve was used to determine the concentration of both OVA-specific and total IgA in fecal extracts.

\subsection{Preparation of DLN Extracts for Multiplex Analysis}

Mice were immunized in the footpad with either $10 \mu \mathrm{g}$ OVA, or OVA + VRP. Six hours after immunizations in both footpads, the draining popliteal lymph nodes from each mouse were harvested, combined and placed in $200 \mu \mathrm{l}$ of PBS containing $1 \times$ protease inhibitors (Roche). The lymph nodes were mechanically homogenized with a pestle, followed by centrifugation at $4^{\circ} \mathrm{C}$. Supernatant was transferred to another tube and frozen on dry ice. Cytokine levels in the samples were analyzed by a Luminex-based assay (Milliplex) purchased from Millipore. For one experiment, levels of 32 cytokines were tested using the Milliplex MAP Mouse Cytokine/Chemokine Premixed 32 Plex (Millipore). Samples were analyzed by Millipore, and 30 cytokines were successfully detected. A 10-plex assay detected G-CSF, GM-CSF IFN- $\gamma$, IL-5, IL-6, IL-12p40, IP-10, MIG, MIP-1 $\beta$, and TNF and was performed by the Clinical Proteomics Laboratory at Thurston Arthritis Research Center, University of North Carolina. Multianalyte profiling was performed on the Luminex-100 system and the XY Platform (Luminex Corporation, Austin, TX). Calibration microspheres for classification and reporter readings, as well as sheath fluid were also from Luminex Corporation. Fluorescence data was acquired by MasterPlex ${ }^{\mathrm{TM}}$ CT 1.2 software (MiraiBio, Alameda, CA). Data analysis was performed using the MasterPlex QT 4.0 system (MiraiBio, Alameda, CA). A five-parameter regression formula was used to calculate the sample concentrations from the standard curves. Cytokines which were undetectable were assigned a value of half of the lowest limit of detection as determined by the standard curve. Cytokine levels which exceeded the standard curve were assigned a value of $10,000 \mathrm{pg} / \mathrm{ml}$. 


\subsection{Surface and intracellular staining of cells from spleen and lymph node}

Spleens or draining popliteal or iliac lymph nodes were harvested at the time points indicated, homogenized through $40 \mu \mathrm{m}$ cell strainers, and cells counted. For intracellular IFN- $\gamma$ staining, spleen cells were cultured in RPMI-10 containing brefeldin A (GolgiPlug, BD Biosciences) either in the presence of OVA peptide (SIINFEKL) or an irrelevant peptide $(2 \mu \mathrm{g} / \mathrm{ml})$ for $5 \mathrm{~h}$ at $37^{\circ}$. Cells were washed and stained at $4^{\circ} \mathrm{C}$ for desired surface receptors with fluorochromeconjugated antibodies specific for CD3, CD8, CD11c, CD19, and CD69 (eBioscience) in 1\% BSA/PBS. Brefeldin A was included in this step if cells were to be stained for IFN- $\gamma$. Cells were fixed in $2 \%$ paraformaldehyde for $15 \mathrm{~min}$ at room temperature. For IFN- $\gamma$ staining, fixed cells were washed and permeabilized in staining buffer containing $0.5 \%$ saponin and stained with anti-IFN- $\gamma\left(\right.$ eBioscience) at $4^{\circ} \mathrm{C}$. Cells were then washed with saponin buffer and analyzed on an Accuri flow cytometer.

\section{Results}

\subsection{VRP with a minimum genome lacking a complete $26 \mathrm{~S}$ subgenomic RNA promoter are an effective adjuvant by intramuscular delivery}

In initial studies of its adjuvant properties, the VRP which were used, designated VRP16M, contained a $59 \mathrm{nt}$ non-coding sequence and a $118 \mathrm{nt} 3$ ' UTR after the $26 \mathrm{~S}$ promoter start site (Fig 1A) [17]. UV inactivation of the VRP RNA indicated that transcription and/or replication of the VRP genome is necessary for its function as an adjuvant [17], but it was unknown if the $26 \mathrm{~S}$ promoter played a role. On a molar basis the $26 \mathrm{~S}$ subgenomic RNA is present at ten times the amount of genomic RNA [20], and this robust transcription may augment or inhibit the VRP adjuvant effect. We addressed this uncertainty by comparing the adjuvant effect of two different VRP genomes: VRP16M or a new VRP genome named VRP(-5) which contains a deletion in the core $26 \mathrm{~S}$ subgenomic promoter and is genetically incapable of producing a subgenomic RNA (Fig 1A). Mice were primed and boosted with OVA alone or OVA in the presence of a low dose of VRP16M or VRP $(-5)\left(10^{3} \mathrm{IU}\right.$, which corresponds to $10^{6} \mathrm{GE}$ ). (VRP IU are based on in vitro infection of BHK-21 cells; in vivo infectivity is undefined.) After the boost we measured anti-OVA IgG in the serum and anti-OVA IgA in fecal extracts. Both VRP genomes significantly increased antibody responses compared to OVA alone (Fig1 B,C), with the VRP $(-5)$ genome inducing a significantly stronger mucosal IgA response. These results show clearly that the $26 \mathrm{~S}$ promoter is not required for the adjuvant effect induced by VRP, so for all subsequent experiments we used the VRP $(-5)$ genome, which will be referred to as simply VRP for the rest of this report.

In all previous studies of VRP adjuvant activity the VRP were injected into the footpad, but because this is an impractical route for human vaccines, we assessed whether VRP would be effective by intramuscular (i.m.) delivery. Mice were primed and boosted with OVA and VRP $\left(10^{5} \mathrm{IU}\right)$ in the footpad or i.m. Anti-OVA serum IgG and fecal IgA titers were significantly increased by both routes of delivery (Fig1 D,E), indicating that i.m. delivery of VRP is just as effective as footpad delivery.

\subsection{VRP are an effective adjuvant at a wide range of doses}

Data shown in Figure 1 demonstrate that VRP injected into the footpad are an effective adjuvant at a relatively low dose $\left(10^{3} \mathrm{IU}\right)$. To evaluate the efficacy of lower doses of VRP delivered i.m., we tested the effect of VRP on anti-OVA immunity after i.m. injection in Balb/c mice using a range of VRP doses between $10^{2}$ and $10^{5} \mathrm{IU}\left(10^{5}-10^{8} \mathrm{GE}\right)$. Titers of anti-OVA IgG in the serum had a clear dose-response, and all tested doses of VRP significantly increased the anti-OVA titers relative to mice immunized with OVA alone (Fig 2A). The mucosal response measured in the fecal extracts demonstrated clear induction of anti-OVA IgA antibodies at all tested VRP doses, with the strongest response at $\geq 10^{4} \mathrm{IU}$ (Fig 2B). 
To examine the VRP dose effect on T cell responses, we primed and boosted C57B1/6 mice i.m. with OVA alone or in the presence of increasing doses of VRP. This mouse strain was used because T cell-reactive OVA peptides are known for this mouse, and it was previously shown that the VRP adjuvant effect is intact in this strain [21]. The dose of OVA used (100 $\mu \mathrm{g}$ ) was based on the previous finding that this higher dose was required for a detectable $\mathrm{T}$ cell response (25). After boost, spleen cells harvested from these mice were incubated in vitro with a CD8-specific OVA peptide, and IFN- $\gamma$ production was measured by intracellular staining and flow cytometric analysis. The percent of detected OVA-responsive CD8 T cells slightly increased with increasing VRP dose, and the response increased significantly at the highest dose of VRP (10 IU) (Fig 3).

\subsection{VRP adjuvant activity requires the presence of VRP in the prime but not in the boost}

Previous data suggested that the mucosal immunity induced by parenteral delivery of VRP may be due to the induction of a mucosal-like environment in the draining lymph node [29]. It is therefore possible that there are long-term effects in the lymph node after prime with VRP which affect the immune response during boost. In addition, it was unknown whether VRP play a more important role during prime or boost, or if both are equally important. We addressed these questions in mice which received a prime and boost with OVA in the footpad. These mice were divided into groups which received no VRP, VRP in prime only, VRP in boost only, VRP in both prime and boost, or VRP and OVA in the contralateral footpad during boost. We performed these studies in the footpad instead of i.m., so that the injection would drain to a single lymph node, focusing any effects. A low VRP dose $\left(10^{3} \mathrm{IU}\right)$ was used to minimize possible effects of VRP in other lymph nodes. Evaluation of anti-OVA IgG in the serum and IgA in fecal extracts demonstrates a comparable adjuvant effect in mice receiving the boost in the same or contralateral footpad as in prime (Fig 4 A,B). The OVA-specific IgG titer was similarly increased when VRP was included in prime only (Fig 4A). However, when VRP was present only in the boost, the IgG titer was increased but to a significantly lower level. A more dramatic effect was observed for fecal anti-OVA IgA. Mice receiving VRP only during the boost had no detectable anti-OVA IgA, but addition of VRP to the prime only induced an IgA response comparable to that seen in mice immunized with VRP during both prime and boost (Fig 4B). After prime with antigen and VRP, we do not observe any mucosal response without an antigen boost (data not shown), so it is apparent that boost with antigen is still required to generate an $\operatorname{Ig} \mathrm{A}$ response.

\subsection{Several inflammatory cytokines are rapidly induced in the draining lymph node after immunization with VRP}

Previous studies of VRP activity have evaluated events in the draining lymph node after boost [29]. Since the events which occur during prime are clearly crucial for the VRP adjuvant activity (Fig 4), we examined the cytokine environment in the draining lymph node 6 hours after prime with VRP by multiplex analysis. We again used footpad rather than intramuscular injection because this route allows us to focus our analysis on a single lymph node. We first measured levels of 30 cytokines in draining popliteal lymph nodes harvested 6 hours after footpad injection with OVA $(10 \mu \mathrm{g})$ or with OVA combined with $10^{4}$ IU VRP. In VRP-injected mice we observed a significant increase in 18 of the 30 measured cytokines (Table 1). Based on the collected data, we selected a panel of 10 cytokines, 9 of which had a large fold increase in response to VRP, and one negative control (IL-12p40). We assessed those cytokine levels after injection of OVA alone or OVA with a range of VRP doses between $10^{1}$ and $10^{5} \mathrm{IU}$. Six hours after immunization, levels of 10 cytokines in lymph node homogenates were measured by a multiplex assay. Of the analyzed factors, four (G-CSF, IFN- $\gamma$, IL-6 and MIP- $1 \beta$ ) were upregulated to relatively high levels at VRP doses of $10^{3}$ IU and above (Fig 5A). Three other cytokines (GM-CSF, IL-5, and TNF) were upregulated at a similar range of VRP doses, although the absolute levels of cytokines were lower than those shown in Figure 5A, and are 
shown separately for clarity (Fig 5B). The chemokines MIG and IP-10 were strongly upregulated from undetectable levels to levels above the maximum limits of the assay at all doses of VRP greater than $10^{1} \mathrm{IU}$, while IL-12p40 was not upregulated at all (data not shown).

\subsection{Increased cellularity and leukocyte activation in the lymph node is dose responsive}

Because VRP clearly induce rapid inflammation in the draining lymph node, we evaluated how the VRP dose affects leukocyte activation and recruitment to the lymph node. It has been previously reported that the cellularity of the draining lymph node dramatically increases after boost with VRP [29]. Here we examined the impact on the lymph node after prime by injection of a range of doses of VRP between $10^{1}$ and $10^{5} \mathrm{IU}$ into the footpads of mice. Draining popliteal lymph nodes were harvested after 6 or 24 hours, and cells were counted and stained with antibodies specific for cell surface markers. Lymph node cellularity was not changed during the first 6 hours post VRP inoculation (data not shown), but after 24 hours lymph node cellularity was significantly increased when compared to diluent alone at VRP doses of $10^{2}$ IU and above (Fig 6A). It was previously observed that after boost with VRP there is a disproportionate increase in the number of $\mathrm{CD} 11 \mathrm{c}+\mathrm{CD} 11 \mathrm{~b}+$ cells in the draining lymph node [29]. Our data show that this is true after prime as well, and we further found that the $>80 \%$ of these cells express F4/80 in addition to CD11c and CD11b. This population constituted a small percentage of the cells in the lymph node in uninjected mice and was significantly increased 24 hours after prime with a VRP dose of $10^{2} \mathrm{IU}$ or greater (Fig 6D). We also examined CD69, an early activation marker on leukocytes [30,31], which has the function of suppressing egress of activated cells from the lymph node [32]. At 6 hours after prime with VRP, CD69 was increased on the total live cell population in mice injected with $10^{3} \mathrm{IU}$ or greater (Fig 6B), similar to the range of VRP doses that upregulated cytokines after 6 hours (Fig 5). By 24 hours, CD69 was upregulated in a dose-responsive manner at all tested VRP doses, and appeared to plateau starting at $10^{4} \mathrm{IU}$ (Fig 6C). The increase in CD69 was not specific to any particular cell type, as T cells, B cells, DCs, and macrophages were all similarly affected (data not shown).

Because the response to VRP may differ somewhat following i.m. injection, we assessed the amount of VRP present in the draining lymph node following footpad or i.m. gastrocnemius injection of VRP-GFP. After 16 hours, we harvested various lymph nodes and detected GFPpositive VRP-infected cells by flow cytometry. After footpad injection, VRP-infected cells were detected almost exclusively in the popliteal lymph node. After i.m. injection, small numbers of GFP-positive cells were observed in the iliac lymph nodes (Fig 6E), but not the inguinal lymph nodes (not shown). Although fewer infected cells were detected following i.m. injection, CD69 levels were elevated in the iliac lymph nodes and much less so in the popliteal lymph node (Fig 6F).

\subsection{The immunity-enhancing environment induced by VRP lasts less than 24 hours}

We hypothesize that inflammation induced by VRP in the draining lymph node plays an important role in the observed adjuvant effect, but it was unknown if antigen must be delivered at the same time as VRP to be affected by this inflammatory environment. To address this question we inoculated mice in the footpad with VRP at time 0 and injected those mice with OVA in the same footpad at the same time or 24 hours before or after the VRP injection. After 4 weeks the mice were boosted in the same way. Anti-OVA IgG in the serum was not significantly increased in mice injected with OVA 24 hours before or after VRP (Fig 7A). Fecal anti-OVA IgA was significantly upregulated when OVA was delivered before VRP, although to a lesser degree than when VRP and OVA were delivered together (Fig 7B). In contrast, injection of OVA 24 hours after VRP resulted in no induction of fecal anti-OVA IgA.

It is possible that this poor mucosal response to OVA delivered after VRP is due not to the kinetics of the VRP-induced immune response to antigen, but rather to VRP-triggered 
alteration of antigen transport to the draining lymph node. We assessed this possibility by immunizing mice in the footpad with OVA labeled with Alexa Fluor 488, either alone, in the presence of VRP, or in mice injected in the footpad 24 hours earlier with VRP. After 6 hours levels of OVA-positive cells in the draining lymph node were detected by flow cytometry. We found that the level of OVA-containing cells in the lymph node was unaffected by coinjection with VRP and was in fact increased in mice injected with VRP 24 hours earlier (Fig 7C). Based on this outcome we conclude that altered antigen transport is unlikely to play a significant role in the response to antigen delivered after VRP.

\section{Discussion}

The findings presented here further demonstrate the potency of VRP as a vaccine adjuvant, reveal new indicators of VRP activity, and will help to define optimal conditions for use of this adjuvant. Comparison of VRP genomes that either contain (VRP16M) or lack (VRP( $(-5))$ the $26 \mathrm{~S}$ promoter revealed that the promoter does not contribute to adjuvant activity. The promoter may in fact reduce the adjuvant effect, as mucosal anti-OVA IgA levels were increased when VRP $(-5)$ was used as an adjuvant. One explanation for this outcome is that nsP gene amplification is necessary for adjuvant activity and may be reduced by the highly active $26 \mathrm{~S}$ promoter competing for RNA synthetic machinery. Another asset of the VRP(-5) genome is that it may reduce the already slim probability of producing a propagation-competent virus during VRP assembly, improving safety. During production of VRP, the unlikely event of nonhomologous RNA-RNA recombination between replicon and both helper RNAs in the packaging cell could result in a recombinant, propagation-competent genome containing the nsP genes linked to the structural genes downstream of their own 26S promoters [20,25]. Because the VRP(-5) genome contains no sequence between the end of nsP4 and the start of the 3'UTR, there is very little sequence in which a productive recombination can occur. Preliminary data has shown clearly reduced incidence of single helper RNA recombinants produced by VRP(-5) (data not shown).

Data shown here demonstrate that i.m. VRP injection, a routine route for human vaccination, is just as effective as footpad injection in the mouse, which was the only route previously tested. We have further shown that humoral adjuvant activity of VRP is maintained at much lower doses than had previously been tested. The practical value of this finding is that use of low doses of VRP in human (or veterinary) vaccines will make this adjuvant more cost-effective. In addition, the need for only a small dose of VRP in a vaccine should help to further minimize risks associated with VRP, namely generation of propagation competent virus and induction of anti-VEE immunity. We did not observe a significant augmentation of the CD8 T cell response at any VRP dose below $10^{5} \mathrm{IU}$. Either higher VRP doses are required to enhance cellular responses, or our assay of cellular immunity is less sensitive than that for humoral immunity. It will be valuable to examine whether CD8-dependent protection from pathogens can be achieved at lower VRP doses.

We have confirmed and extended previous data demonstrating that VRP injection generates an inflammatory environment in the draining lymph node [29]. By multiplex analysis we observed dose-dependent upregulation of many inflammatory cytokines and chemokines in the draining lymph node following injection of VRP, indicative of an innate immune response. These results are generally consistent with the cytokines previously observed after boost with VRP [29]. IL-6 and TNF secretion have previously been demonstrated in VRP-infected DCs in vitro [23], and most of the other cytokines measured here can also be secreted by myeloid cells such as macrophages and DCs, including G-CSF, GM-CSF, IP-10, MIG, MIP-1 $\beta$, and IFN- $\gamma$ [33-38], while NK cells are another likely source of IFN- $\gamma$ [39]. It should also be noted that type 1 interferons, which were not tested in this assay but are a central marker of innate immune induction, have been observed in mouse serum within 6 hours of VRP injection 
(unpublished results). In addition to cytokine secretion, we identified many other indicators of innate immune activation in the draining lymph node such as rapid upregulation of CD69 and increased lymph node size and cellularity, with a disproportionate increase in monocytic cells which express the surface receptors CD11b, CD11c, and F4/80. All of these effects were doseresponsive. CD69 may play a role in the observed increase in lymph node cellularity by preventing lymph node egress of CD69-expressing cells [32]. Similar CD69 upregulation has been observed on various leukocyte subsets following infection with the VEE virus [40], or injection of other adjuvants such as Poly(I:C) [32], CpG [41], and U1 RNA [42], and it is likely upregulated in response to inflammatory cytokines such as those observed here $[30,31,43]$. We hypothesize that VRP stimulation of pattern recognition receptors triggers secretion of such cytokines in the draining lymph node, which in turn drive leukocyte recruitment and activation, resulting in enhanced $\mathrm{T}$ cell and B cell memory.

Footpad and i.m. VRP injection are effective at similar doses, yet we identified many more VRP-infected cells in draining lymph nodes following footpad injection. Even so, after i.m. injection we observed robust upregulation of CD69 in the iliac lymph nodes, suggesting that lymph node activity is still relevant by this route. It may simply be that even a small number of VRP-infected cells are sufficient to augment immune activity in the lymph node. It is also possible that after i.m. injection not all VRP-infected lymph node cells were detected due to trafficking of VRP to multiple lymph nodes, some of which were not easily isolated, such as deep inguinal nodes. Alternately, VRP may activate uninfected macrophages and DCs in the muscle which then migrate to the lymph nodes and drive an inflammatory, immune-enhancing response.

If the inflammatory environment induced in the draining lymph node by VRP is driving the adjuvant effect, then it is important to know how long this immune enhancing environment effects persists. The observed absence of adjuvant effect for antigen injected 24 hours after VRP indicates that the immune-enhancing events triggered by VRP have come and gone within the first 24 hours. We also observe no role for long term VRP-induced changes in the draining lymph node, as boost need not occur in the same site as prime. This result suggests that VRPcontaining human vaccines will not cause immunity against irrelevant antigens introduced $\geq 24 \mathrm{hrs}$ after immunization, an important safety consideration. Interestingly, we found that VRP will enhance immunity to antigen already present at the injection site, for a mucosal immune response was generated against OVA injected 24 hours before VRP.

The finding that VRP are dispensable during antigen boost reveals that events which occur during a VRP-containing primary immunization are sufficient to set the stage for an enhanced immune response upon subsequent exposure to the same antigen. It may simply be that strong $\mathrm{T}$ and $\mathrm{B}$ cell memory are established during prime with the help of the innate immune activation in response to VRP, so during boost further innate immune-driven costimulation becomes unnecessary $[44,45]$ A similar requirement for the presence of adjuvant only in prime has been occasionally demonstrated [6,46,47], but it is unclear whether this holds true for most adjuvants, or only a unique subset. In our adjuvant model, mucosal immunity is not observed after prime with antigen and VRP (data not shown), but can be detected only after boost with antigen (with or without VRP). It therefore appears that after immunization with VRP the nature of the immune response to co-delivered antigen has been fully established, and boost is required simply for further stimulation of lymphocyte expansion and antibody production.

Alternatively, it is possible that the lack of VRP activity in boost is due to anti-VRP immunity generated during prime, but this is unlikely, as anti-VRP immunity is not detected after a single VRP injection [20].

The many inflammatory events which occur after VRP injection will not only inform our studies of the VRP adjuvant mechanism, but should also be useful as indicators of adjuvant 
activity. We have shown that these effects increase proportionally to dose, so it should be possible to correlate defined inflammatory events with successful induction of various aspects of the immune response. These inflammatory indicators may be used as clinical markers of adjuvant efficacy, and could be tracked in serum in clinical trials, serving as a link between animal and human studies. We believe that the potential of VRP as a human vaccine adjuvant is considerable, as VRP have a clean record of safety [48,49], robust activity, and simple formulation. Previous studies have demonstrated that VRP can induce VEE-specific immunity $[20,50]$, but it remains uncertain whether such immunity will limit activity of VRP in subsequent immunizations. While this remains a concern which must be addressed, we have demonstrated here that VRP are effective at low doses which can be limited to use in the primary immunization. By using limited amounts of VRP in this way we can reduce anti-VEE titers, helping to alleviate this concern. These advantages, combined with the ability of VRP to induce mucosal immunity, may make VRP a safe and promising adjuvant to improve new and existing vaccines.

\section{Acknowledgments}

We thank Alan Whitmore for valuable experimental advice and Nancy Davis for helpful feedback and critical review of this manuscript. We also thank Martha Collier for the production of the VRP and Benjamin Steil for the calculation of VRP genome equivalents. The VRP(-5) genome was constructed by Karl Ljungberg. This work was supported by funding from the National Institutes of Health: U01-AI070976.

\section{References}

1. Lavelle EC. Generation of improved mucosal vaccines by induction of innate immunity. Cell Mol Life Sci 2005 Dec;62(23):2750-2770. [PubMed: 16237500]

2. Kwissa M, Kasturi SP, Pulendran B. The science of adjuvants. Expert review of vaccines 2007 Oct;6 (5):673-684. [PubMed: 17931149]

3. McKee AS, Munks MW, Marrack P. How do adjuvants work? Important considerations for new generation adjuvants. Immunity 2007 Nov;27(5):687-690. [PubMed: 18031690]

4. Mestecky J. The common mucosal immune system and current strategies for induction of immune responses in external secretions. J Clin Immunol 1987 Jul;7(4):265-276. [PubMed: 3301884]

5. Neutra MR, Kozlowski PA. Mucosal vaccines: the promise and the challenge. Nature reviews 2006 Feb;6(2):148-158.

6. McCluskie MJ, Weeratna RD, Payette PJ, Davis HL. Parenteral and mucosal prime-boost immunization strategies in mice with hepatitis B surface antigen and CpG DNA. FEMS Immunol Med Microbiol 2002 Feb 18;32(3):179-185. [PubMed: 11934561]

7. Egan MA, Chong SY, Hagen M, Megati S, Schadeck EB, Piacente P, et al. A comparative evaluation of nasal and parenteral vaccine adjuvants to elicit systemic and mucosal HIV-1 peptide-specific humoral immune responses in cynomolgus macaques. Vaccine 2004 Sep 9;22(27-28):3774-3788. [PubMed: 15315859]

8. Enioutina EY, Visic D, McGee ZA, Daynes RA. The induction of systemic and mucosal immune responses following the subcutaneous immunization of mature adult mice: characterization of the antibodies in mucosal secretions of animals immunized with antigen formulations containing a vitamin D3 adjuvant. Vaccine 1999 Aug 6;17(23-24):3050-3064. [PubMed: 10462240]

9. Coffin SE, Clark SL, Bos NA, Brubaker JO, Offit PA. Migration of antigen-presenting B cells from peripheral to mucosal lymphoid tissues may induce intestinal antigen-specific IgA following parenteral immunization. J Immunol 1999 Sep 15;163(6):3064-3070. [PubMed: 10477570]

10. Coffin SE, Klinek M, Offit PA. Induction of virus-specific antibody production by lamina propria lymphocytes following intramuscular inoculation with rotavirus. J Infect Dis 1995 Sep;172(3):874878. [PubMed: 7658087]

11. Charles PC, Brown KW, Davis NL, Hart MK, Johnston RE. Mucosal Immunity Induced by Parenteral Immunization with a Live Attenuated Venezuelan Equine Encephalitis Virus Vaccine Candidate. Virology 1997;228(2):153-160. [PubMed: 9123821] 
12. Musey L, Ding Y, Elizaga M, Ha R, Celum C, McElrath MJ. HIV-1 vaccination administered intramuscularly can induce both systemic and mucosal T cell immunity in HIV-1-uninfected individuals. J Immunol 2003 Jul 15;171(2):1094-1101. [PubMed: 12847284]

13. Harrington PR, Yount B, Johnston RE, Davis N, Moe C, Baric RS. Systemic, mucosal, and heterotypic immune induction in mice inoculated with Venezuelan equine encephalitis replicons expressing Norwalk virus-like particles. Journal of virology 2002 Jan;76(2):730-742. [PubMed: 11752163]

14. LoBue AD, Lindesmith L, Yount B, Harrington PR, Thompson JM, Johnston RE, et al. Multivalent norovirus vaccines induce strong mucosal and systemic blocking antibodies against multiple strains. Vaccine 2006 Jun 12;24(24):5220-5234. [PubMed: 16650512]

15. Peters C, Peng X, Douven D, Pan ZK, Paterson Y. The induction of HIV Gag-specific CD8+ T cells in the spleen and gut-associated lymphoid tissue by parenteral or mucosal immunization with recombinant Listeria monocytogenes HIV Gag. J Immunol 2003 May 15;170(10):5176-5187. [PubMed: 12734365]

16. Kauppi M, Eskola J, Kayhty H. Anti-capsular polysaccharide antibody concentrations in saliva after immunization with Haemophilus influenzae type b conjugate vaccines. Pediatr Infect Dis J 1995 Apr; 14(4):286-294. [PubMed: 7603810]

17. Thompson JM, Whitmore AC, Konopka JL, Collier ML, Richmond EMB, Davis NL, et al. Mucosal and systemic adjuvant activity of alphavirus replicon particles. Proceedings of the National Academy of Sciences of the United States of America 20062006 March 7;103(10):3722-3727.

18. Craig CP, Reynolds SL, Airhart JW, Staab EV. Alterations in immune responses by attenuated Venezuelan equine encephalitis vaccine. I. Adjuvant effect of VEE virus infection in guinea pigs. $J$ Immunol 1969 May;102(5):1220-1227. [PubMed: 4181548]

19. Howard RJ, Craig CP, Trevino GS, Dougherty SF, Mergenhagen SE. Enhanced humoral immunity in mice infected with attenuated Venezuelan equine encephalitis virus. J Immunol 1969 Oct;103(4): 699-707. [PubMed: 4186914]

20. Pushko P, Parker M, Ludwig GV, Davis NL, Johnston RE, Smith JF. Replicon-helper systems from attenuated Venezuelan equine encephalitis virus: expression of heterologous genes in vitro and immunization against heterologous pathogens in vivo. Virology 1997 Dec 22;239(2):389-401. [PubMed: 9434729]

21. Thompson JM, Whitmore AC, Staats HF, Johnston RE. Alphavirus replicon particles acting as adjuvants promote CD8(+) T cell responses to co-delivered antigen. Vaccine. 2008 Jun 9;

22. LoBue AD, Thompson JM, Lindesmith L, Johnston RE, Baric RS. Alphavirus-adjuvanted noroviruslike particle vaccines: heterologous, humoral, and mucosal immune responses protect against murine norovirus challenge. Journal of virology 2009 Apr;83(7):3212-3227. [PubMed: 19176631]

23. Moran TP, Burgents JE, Long B, Ferrer I, Jaffee EM, Tisch RM, et al. Alphaviral vector-transduced dendritic cells are successful therapeutic vaccines against neu-overexpressing tumors in wild-type mice. Vaccine 2007 Sep 4;25(36):6604-6612. [PubMed: 17675184]

24. Moran TP, Collier M, McKinnon KP, Davis NL, Johnston RE, Serody JS. A novel viral system for generating antigen-specific T cells. J Immunol 2005 Sep 1;175(5):3431-3438. [PubMed: 16116238]

25. Davis NL, Caley IJ, Brown KW, Betts MR, Irlbeck DM, McGrath KM, et al. Vaccination of macaques against pathogenic simian immunodeficiency virus with Venezuelan equine encephalitis virus replicon particles. Journal of virology 2000 Jan;74(1):371-378. [PubMed: 10590126]

26. Davis NL, Powell N, Greenwald GF, Willis LV, Johnson BJ, Smith JF, et al. Attenuating mutations in the E2 glycoprotein gene of Venezuelan equine encephalitis virus: construction of single and multiple mutants in a full-length cDNA clone. Virology 1991 Jul;183(1):20-31. [PubMed: 2053280]

27. Schafer A, Whitmore AC, Konopka JL, Johnston RE. Replicon particles of Venezuelan equine encephalitis virus as a reductionist murine model for encephalitis. Journal of virology 2009 May;83 (9):4275-4286. [PubMed: 19225006]

28. Aida Y, Pabst MJ. Removal of endotoxin from protein solutions by phase separation using Triton X-114. J Immunol Methods 1990 Sep 14;132(2):191-195. [PubMed: 2170533]

29. Thompson JM, Nicholson MG, Whitmore AC, Zamora M, West A, Iwasaki A, et al. Nonmucosal alphavirus vaccination stimulates a mucosal inductive environment in the peripheral draining lymph node. J Immunol 2008 Jul 1;181(1):574-585. [PubMed: 18566424] 
30. Marzio R, Mauel J, Betz-Corradin S. CD69 and regulation of the immune function. Immunopharmacol Immunotoxicol 1999 Aug;21(3):565-582. [PubMed: 10466080]

31. Testi R, D'Ambrosio D, De Maria R, Santoni A. The CD69 receptor: a multipurpose cell-surface trigger for hematopoietic cells. Immunol Today 1994 Oct;15(10):479-483. [PubMed: 7945773]

32. Shiow LR, Rosen DB, Brdickova N, Xu Y, An J, Lanier LL, et al. CD69 acts downstream of interferonalpha/beta to inhibit S1P1 and lymphocyte egress from lymphoid organs. Nature 2006 Mar 23;440 (7083):540-544. [PubMed: 16525420]

33. Roberts AW. G-CSF: a key regulator of neutrophil production, but that's not all! Growth Factors 2005 Mar;23(1):33-41. [PubMed: 16019425]

34. Pelus LM, Broxmeyer HE, DeSousa M, Moore MA. Heterogeneity among resident murine peritoneal macrophages: separation and functional characterization of monocytoid cells producing granulocytemacrophage colony-stimulating factor (GM-CSF) and responding to regulation by lactoferrin. J Immunol 1981 Mar;126(3):1016-1021. [PubMed: 6970210]

35. Farber JM. Mig and IP-10: CXC chemokines that target lymphocytes. J Leukoc Biol 1997 Mar;61 (3):246-257. [PubMed: 9060447]

36. Wolpe SD, Davatelis G, Sherry B, Beutler B, Hesse DG, Nguyen HT, et al. Macrophages secrete a novel heparin-binding protein with inflammatory and neutrophil chemokinetic properties. The Journal of experimental medicine 1988 Feb 1;167(2):570-581. [PubMed: 3279154]

37. Suto A, Nakajima H, Tokumasa N, Takatori H, Kagami S, Suzuki K, et al. Murine plasmacytoid dendritic cells produce IFN-gamma upon IL-4 stimulation. J Immunol 2005 Nov 1;175(9):56815689. [PubMed: 16237058]

38. Frucht DM, Fukao T, Bogdan C, Schindler H, O'Shea JJ, Koyasu S. IFN-gamma production by antigen-presenting cells: mechanisms emerge. Trends Immunol 2001 Oct;22(10):556-560. [PubMed: 11574279]

39. Boehm U, Klamp T, Groot M, Howard JC. Cellular responses to interferon-gamma. Annu Rev Immunol 1997;15:749-795. [PubMed: 9143706]

40. Bennett AM, Elvin SJ, Wright AJ, Jones SM, Phillpotts RJ. An immunological profile of Balb/c mice protected from airborne challenge following vaccination with a live attenuated Venezuelan equine encephalitis virus vaccine. Vaccine 2000 Sep 15;19(2-3):337-347. [PubMed: 10930689]

41. Sun S, Zhang X, Tough DF, Sprent J. Type I interferon-mediated stimulation of T cells by CpG DNA. The Journal of experimental medicine 1998 Dec 21;188(12):2335-2342. [PubMed: 9858519]

42. Kelly-Scumpia KM, Nacionales DC, Scumpia PO, Weinstein JS, Narain S, Moldawer LL, et al. In vivo adjuvant activity of the RNA component of the Sm/RNP lupus autoantigen. Arthritis Rheum 2007 Oct;56(10):3379-3386. [PubMed: 17907192]

43. Marshall JD, Heeke DS, Abbate C, Yee P, Van Nest G. Induction of interferon-gamma from natural killer cells by immunostimulatory CpG DNA is mediated through plasmacytoid-dendritic-cellproduced interferon-alpha and tumour necrosis factor-alpha. Immunology 2006 Jan;117(1):38-46. [PubMed: 16423039]

44. Fujii S, Liu K, Smith C, Bonito AJ, Steinman RM. The linkage of innate to adaptive immunity via maturing dendritic cells in vivo requires CD40 ligation in addition to antigen presentation and CD80/86 costimulation. The Journal of experimental medicine 2004 Jun 21;199(12):1607-1618. [PubMed: 15197224]

45. Dutton RW, Bradley LM, Swain SL. T cell memory. Annu Rev Immunol 1998;16:201-223. [PubMed: 9597129]

46. Staats HF, Ennis FA Jr. IL-1 is an effective adjuvant for mucosal and systemic immune responses when coadministered with protein immunogens. J Immunol 1999 May 15;162(10):6141-6147. [PubMed: 10229857]

47. Honko AN, Sriranganathan N, Lees CJ, Mizel SB. Flagellin is an effective adjuvant for immunization against lethal respiratory challenge with Yersinia pestis. Infection and immunity $2006 \mathrm{Feb} ; 74(2)$ : 1113-1120. [PubMed: 16428759]

48. Reap EA, Morris J, Dryga SA, Maughan M, Talarico T, Esch RE, et al. Development and preclinical evaluation of an alphavirus replicon particle vaccine for cytomegalovirus. Vaccine 2007 Oct 16;25 (42):7441-7449. [PubMed: 17870214] 
49. Hubby B, Talarico T, Maughan M, Reap EA, Berglund P, Kamrud KI, et al. Development and preclinical evaluation of an alphavirus replicon vaccine for influenza. Vaccine 2007 Nov 23;25(48): 8180-8189. [PubMed: 17961878]

50. Davis NL, Brown KW, Johnston RE. A viral vaccine vector that expresses foreign genes in lymph nodes and protects against mucosal challenge. J Virol 1996 June 1;70(6):3781-3787. 1996. [PubMed: 8648713] 


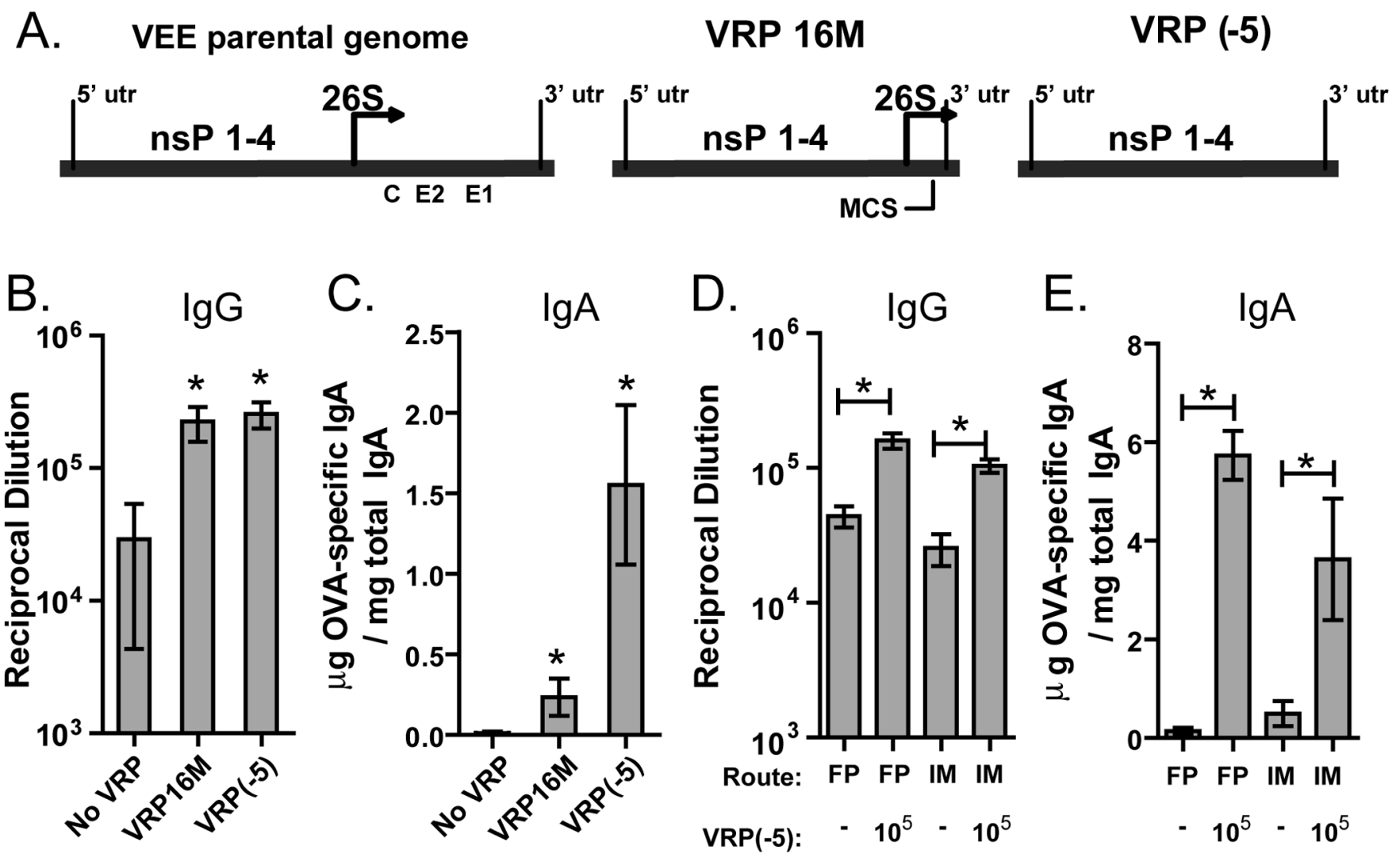

Fig. 1.

VRP adjuvant activity is intact when using intramuscular delivery of VRP which lack the 26S promoter. (A) The VEE parental genome contains sequence for four nsPs and a $26 \mathrm{~S}$ promoter followed by a polyprotein which is processed to produce the capsid and two envelope glycoproteins (C, E1, E2). The VRP genome lacks the structural protein sequences. VRP16M contains 16 nucleotides and a multiple cloning site (MCS) after the $26 \mathrm{~S}$ promoter, while VRP $(-5)$ lacks the sequence between the nsP4 gene and the 3'UTR, including the 26S start site. (B $\& \mathrm{C}) \mathrm{Balb} / \mathrm{c}$ mice were primed and boosted in the footpad with OVA (10 $\mu \mathrm{g})$ alone or in a coinjection with $\operatorname{VRP} 16 \mathrm{M}$ or $\operatorname{VRP}(-5)\left(10^{3} \mathrm{IU}, \approx 10^{6} \mathrm{GE}\right)$. (D \& E) For analysis of the route of immunization, Balb/c mice were primed and boosted either by footpad or intramuscular injection with OVA $(10 \mu \mathrm{g})$ in the absence or presence of VRP $(-5)\left(10^{5} \mathrm{IU}, \approx 10^{8} \mathrm{GE}\right)$. Levels of anti-OVA IgG in the serum (B \& D) and anti-OVA IgA in fecal extracts (C \& E) were determined by ELISA. Six mice per group were injected, and values represent the geometric mean $+/-$ SEM. Statistical significance $(\mathrm{p}<0.05)$ was determined by $t$ test relative to immunoglobulin levels detected for mice injected with OVA only, unless otherwise indicated. Similar results were achieved in two separate experiments. 

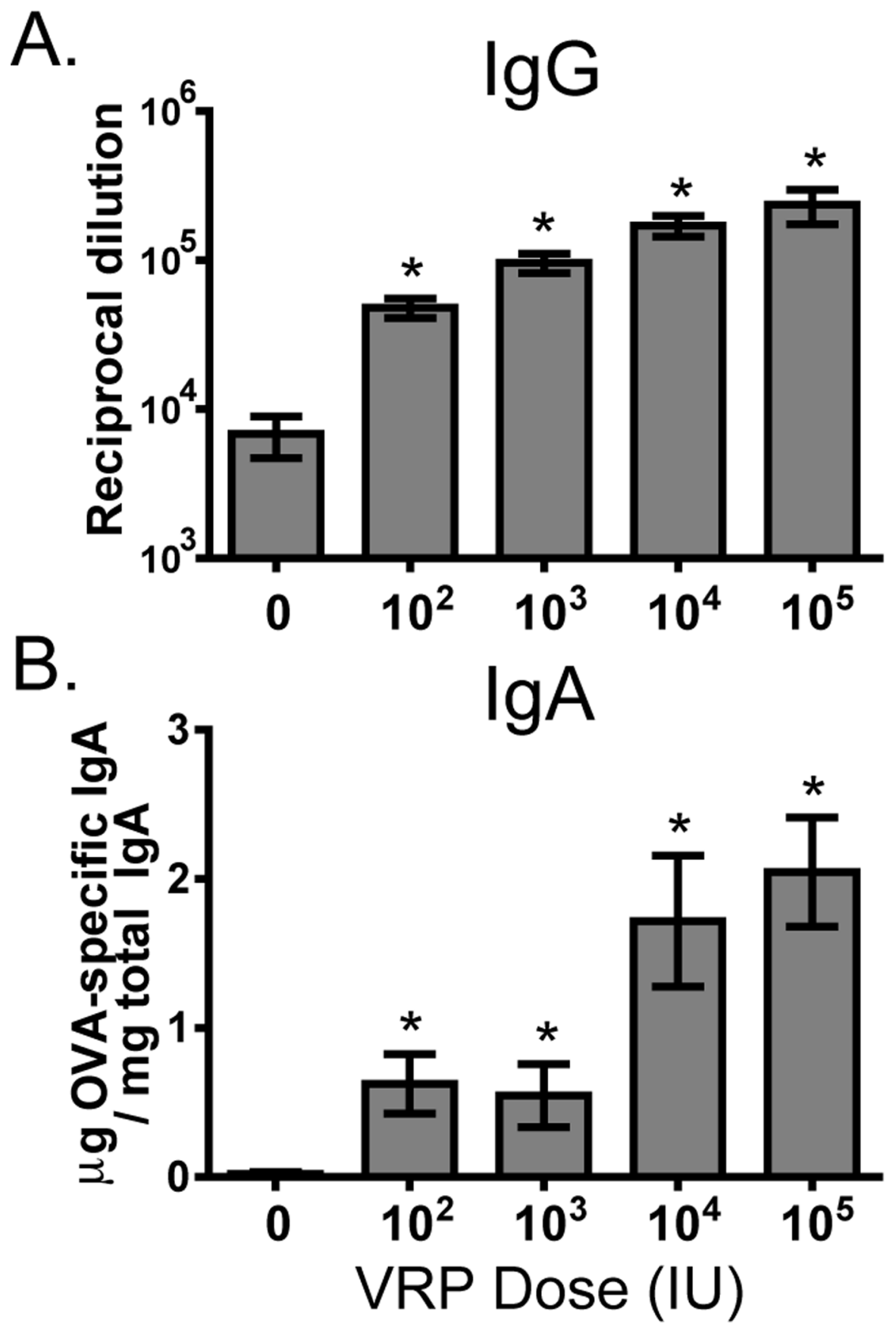

Fig. 2.

VRP are an effective adjuvant at a wide range of doses. Balb/c mice were primed and boosted i.m. with OVA $(10 \mu \mathrm{g})$ in the absence or presence of the indicated dose (infectious units) of VRP $\left(1 \mathrm{IU} \approx 10^{3} \mathrm{GE}\right)$. After boost, anti-OVA serum IgG $(\mathrm{A})$ and anti-OVA fecal IgA (B) were measured by ELISA. Six mice per group were injected, and values represent the geometric mean $+/-$ SEM. Statistical significance $(\mathrm{p}<0.05)$ was determined by $\mathrm{t}$ test relative to OVA only. 


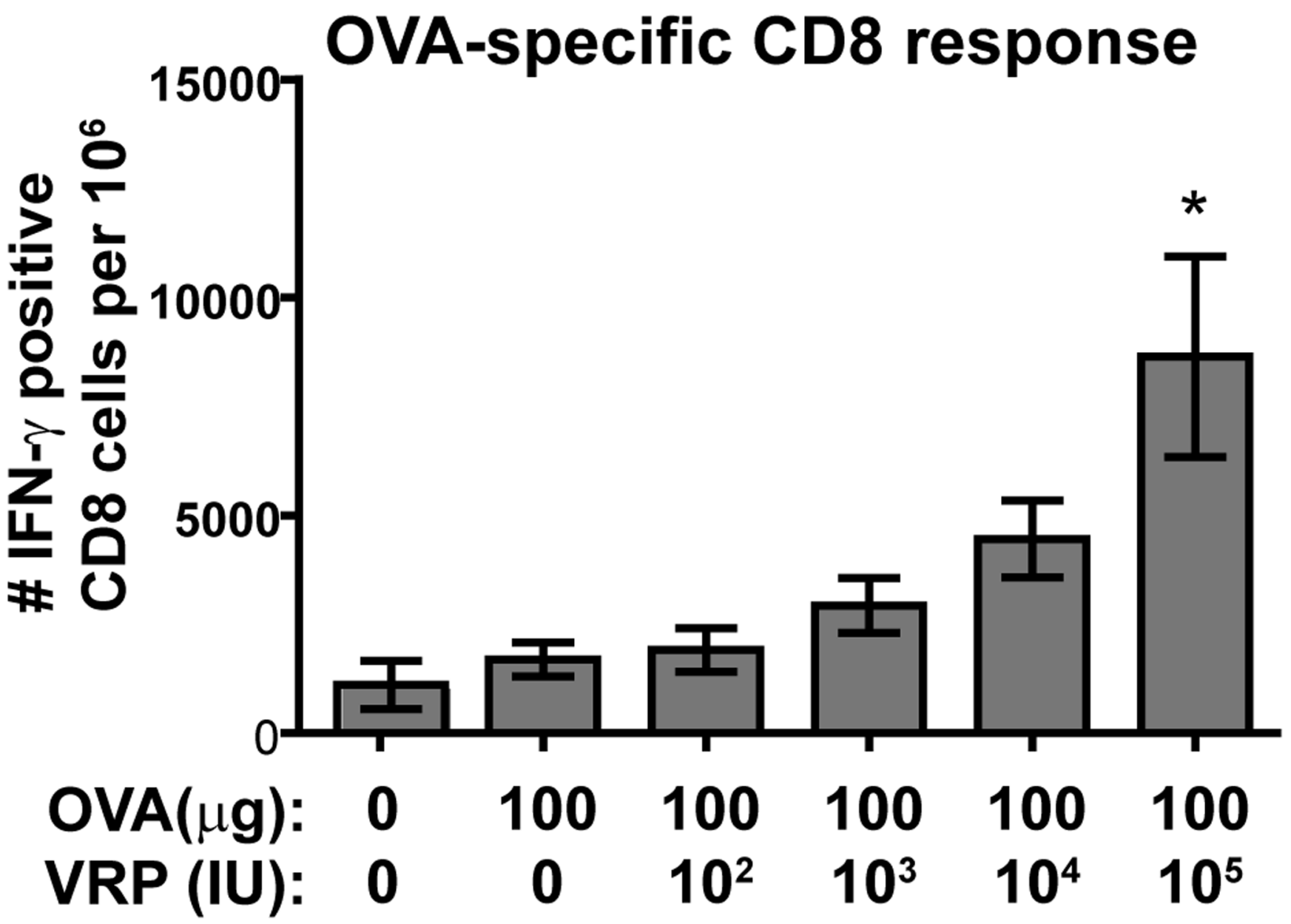

Fig 3.

C57B1/6 mice were primed and boosted i.m. with OVA $(10 \mu \mathrm{g})$ alone or in coinjections with the indicated VRP dose $\left(1 \mathrm{IU} \approx 10^{3} \mathrm{GE}\right) .8$ days after boost, spleens were harvested and $4 \times 10^{6}$ spleen cells incubated with OVA peptide $(2 \mu \mathrm{g} / \mathrm{ml})$ or an irrelevant peptide. Spleens from uninjected mice were assayed as well. After 5 hours, surface CD8 and intracellular IFN$\gamma$ were stained and measured by flow cytometry. There was no response to irrelevant peptide. For OVA stimulated cells, IFN- $\gamma$-positive CD8 T cells are shown. Six mice per group were injected, and statistical significance $(\mathrm{p}<0.05)$ was determined by $\mathrm{t}$ test relative to OVA only. 


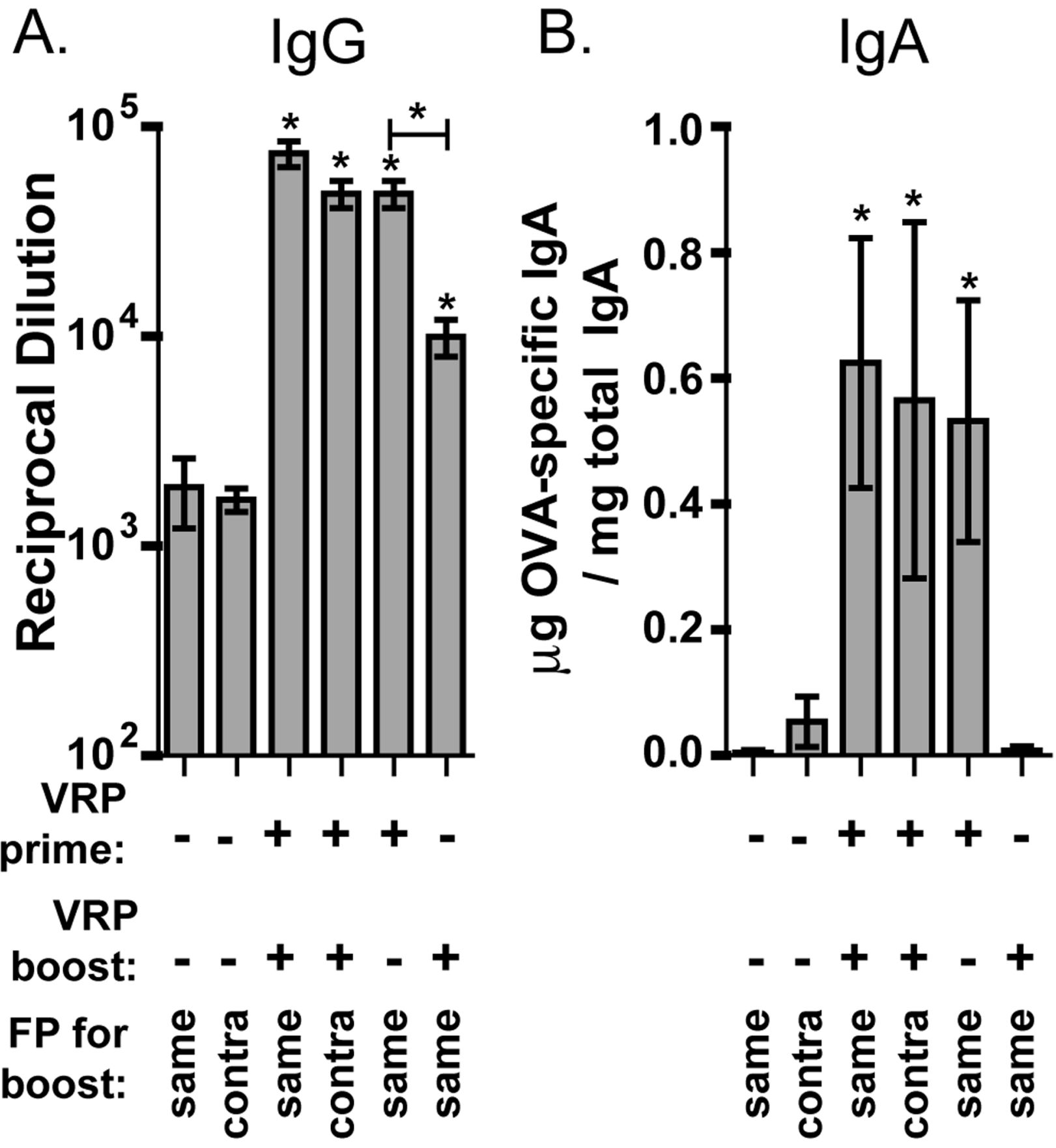

Fig. 4.

VRP are required only during prime to induce a mucosal adjuvant effect. Balb/c mice were primed in the footpad with OVA $(10 \mu \mathrm{g})$ alone or in a coinjection with VRP $\left(10^{3} \mathrm{IU}, \approx 10^{6}\right.$ $\mathrm{GE})$. Mice were boosted in the same way either in the same or contralateral footpad. Other mice were primed and boosted with OVA, but received VRP only in prime, or in boost.After boost, anti-OVA serum IgG (A) and anti-OVA fecal IgA (B) were measured by ELISA. Six mice per group were injected, and values represent the geometric mean $+/-$ SEM. Statistical significance $(\mathrm{p}<0.05)$ was determined by $t$ test relative to OVA only, or as indicated. Similar results were achieved in two separate experiments. 

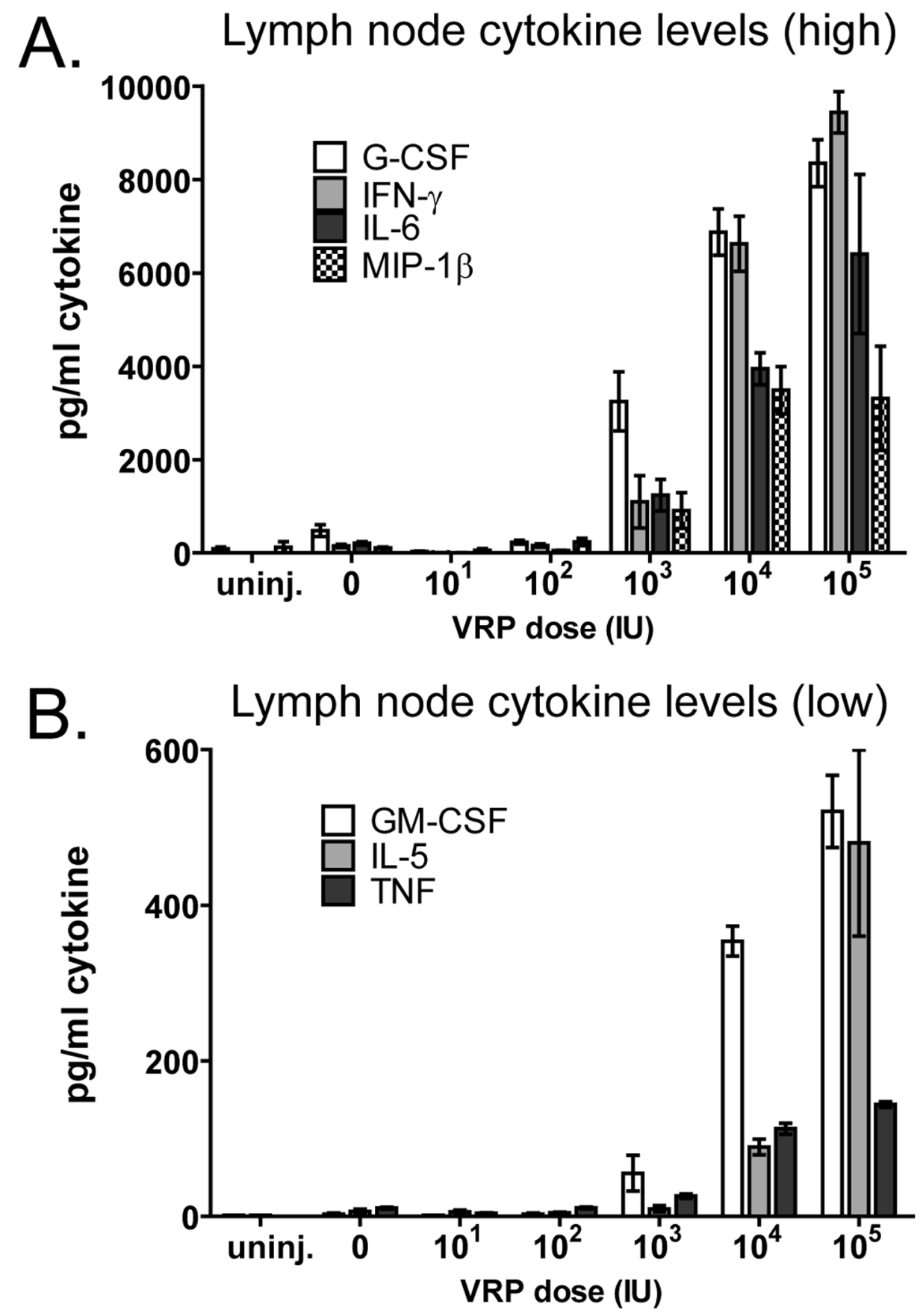

Fig. 5.

VRP trigger rapid secretion of inflammatory cytokines in the draining lymph node. Balb/c mice were injected in the footpad with OVA $(10 \mu \mathrm{g})$ alone or in the presence of VRP at the indicated dose ( $1 \mathrm{IU} \approx 10^{3} \mathrm{GE}$ ). After 6 hours the draining popliteal lymph node was harvested, homogenized, and cytokine levels in the homogenate analyzed by multiplex analysis. Values represent the geometric mean $+/-$ SEM. For cytokines which were undetectable, a value of one half of the lower limit of detection was assigned. The maximum limit of detection was $10,000 \mathrm{pg} / \mathrm{ml}$. Cytokines detected at levels above $1000 \mathrm{pg} / \mathrm{ml}$ (A) are shown separately from those detected at lower levels (B). Four mice per group were injected, and values represent the geometric mean +/- SEM. 

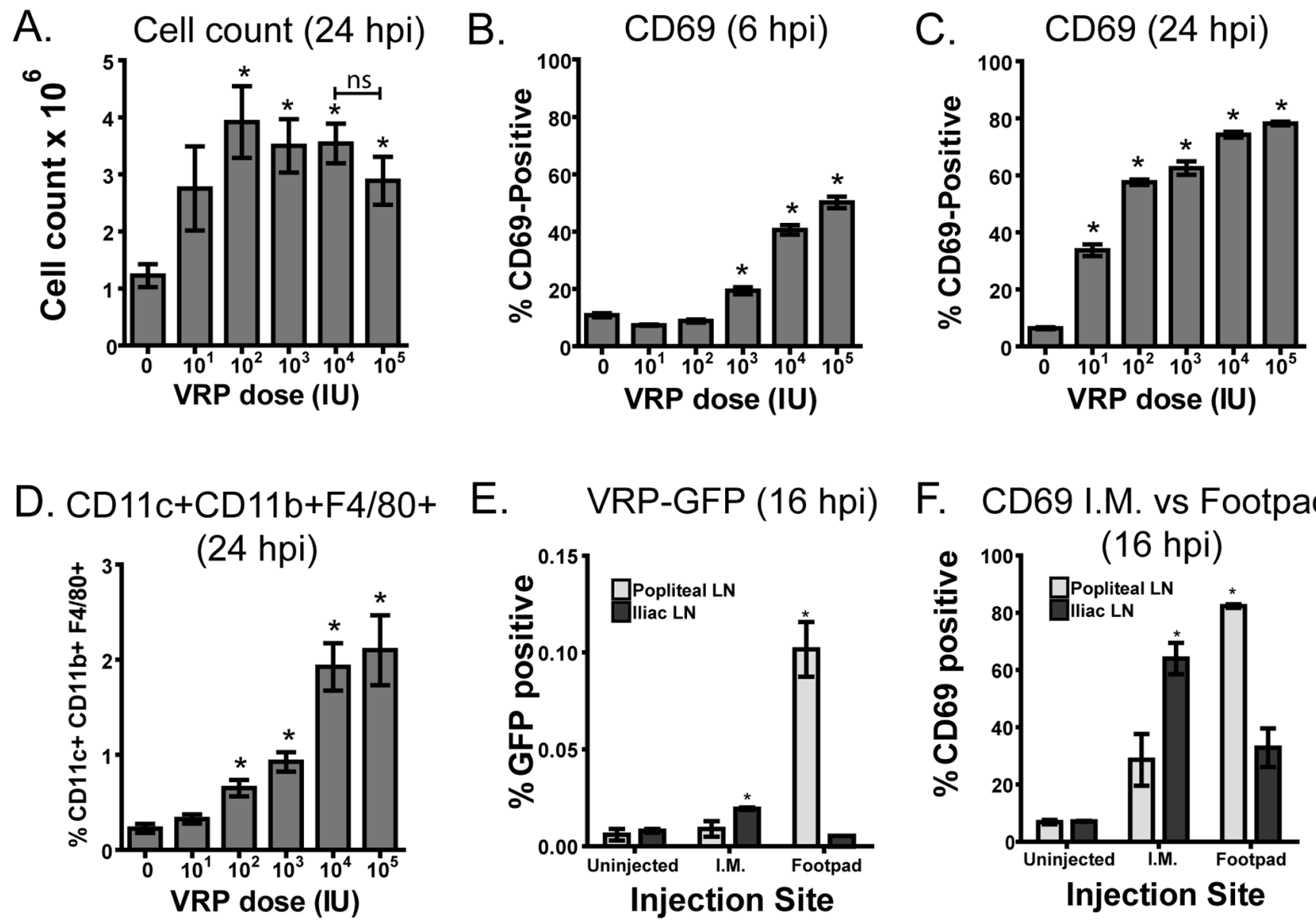

Fig. 6.

VRP-induced inflammation in the draining lymph node is dose responsive. Balb/c mice were injected with diluent or VRP at the indicated dose $\left(1 \mathrm{IU} \approx 10^{3} \mathrm{GE}\right)$. Draining lymph nodes were harvested after 6 or 24 hours post injection (hpi), homogenized, and cells counted (A). Expression of CD11b, CD11c, F4/80 and CD69 was identified by fluorescent antibody staining and analysis by flow cytometry (B-D). Results were gated on live cells as determined by forward and side scatter, and receptor expression is shown as a percent of total live cells. Four mice per group were injected, and values represent the geometric mean +/- SEM. Statistical significance $(\mathrm{p}<0.05)$ was determined by $t$ test relative to diluent. Similar results were achieved in at least two separate experiments. 

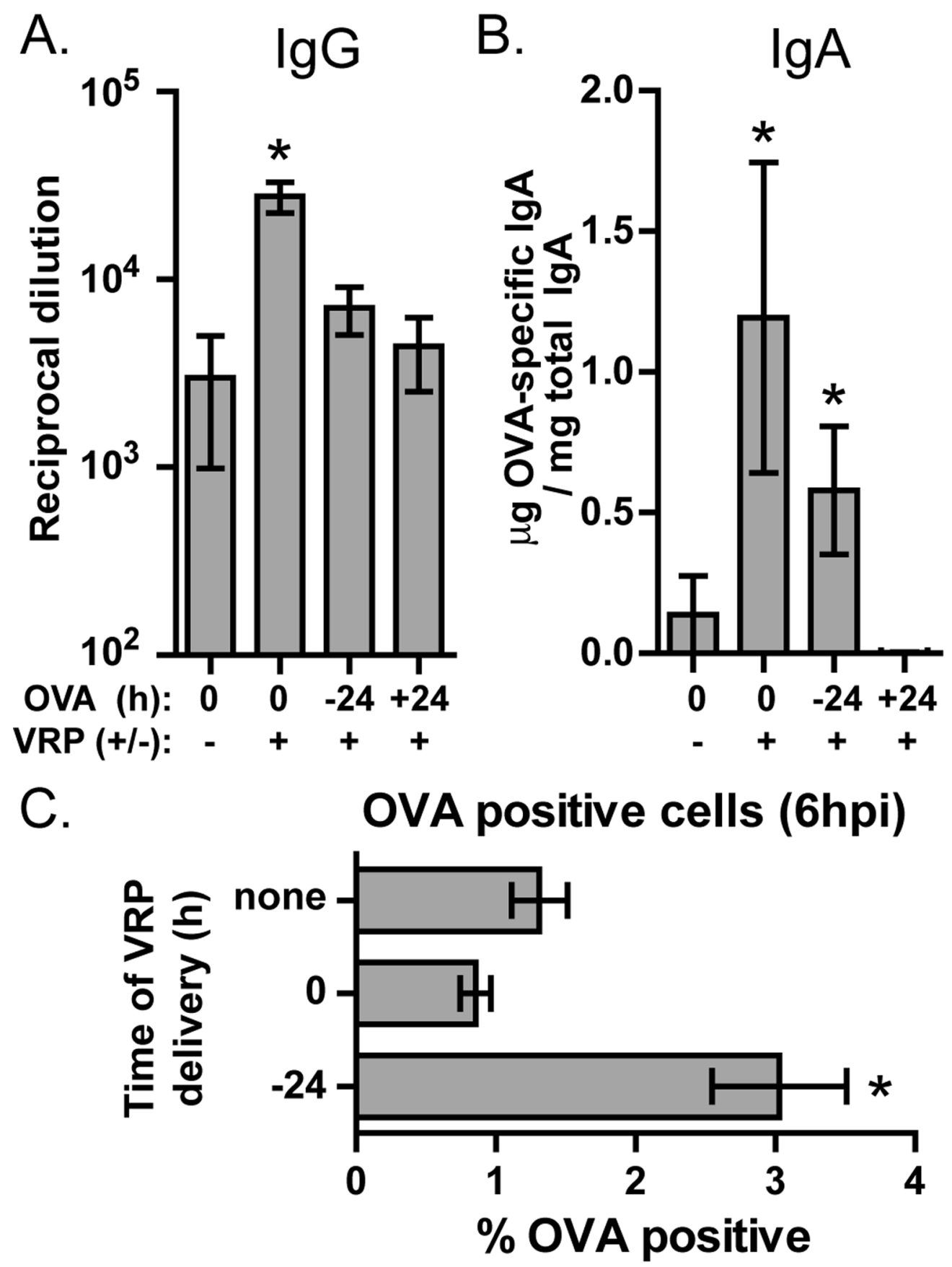

Fig. 7.

VRP-induced inflammation does not affect the mucosal response to antigens delivered 24 hours after VRP. Balb/c mice were primed and boosted with OVA alone or in the presence of VRP $\left(10^{5} \mathrm{IU}, \approx 10^{8} \mathrm{GE}\right)$. VRP was delivered at time 0 and OVA was delivered either at time $0,-24$ hours, or +24 hours, for both prime and boost. After boost, anti-OVA serum IgG (A) and antiOVA fecal $\operatorname{IgA}(\mathrm{B})$ were measured by ELISA. In (C), mice were injected in the footpad with OVA ( $0.5 \mathrm{ug})$ conjugated to Alexa-Fluor-488. In some mice, VRP $\left(10^{5} \mathrm{IU}, \approx 10^{8} \mathrm{GE}\right)$ was injected with OVA, and some mice were injected with VRP $\left(10^{5} \mathrm{IU}, \approx 10^{8} \mathrm{GE}\right) 24$ hours before OVA injection. After 6 hours the draining popliteal lymph node was harvested, homogenized, and analyzed by flow cytometry for the presence of OVA-positive cells, based on detection of 
cells containing Alexa Fluor-488. Six mice per group were injected, and values represent the geometric mean $+/-$ SEM. Statistical significance $(\mathrm{p}<0.05)$ was determined by $\mathrm{t}$ test relative to OVA only. 
Table 1

Cytokine levels in draining lymph node homogenate 6 hours post inoculation $(\mathrm{pg} / \mathrm{ml} \pm \mathrm{SEM})$

\begin{tabular}{|c|c|c|}
\hline & OVA $^{a}$ & $\mathrm{OVA}+\mathrm{VRP}^{a}$ \\
\hline Eotaxin & $190 \pm 34$ & $412 \pm 97$ \\
\hline G-CSF & $115 \pm 26$ & $1918 \pm 191 *$ \\
\hline GM-CSF & $2 \pm 0$ & $293 \pm 37 *$ \\
\hline M-CSF & $24 \pm 10$ & $60 \pm 4 *$ \\
\hline IFN- $\gamma$ & $2 \pm 0$ & $724 \pm 118 *$ \\
\hline IL-1 $\beta$ & $113 \pm 25$ & $156 \pm 8$ \\
\hline IL-2 & $55 \pm 2$ & $56 \pm 1$ \\
\hline IL-3 & $2 \pm 0$ & $3 \pm 2$ \\
\hline IL-4 & $3 \pm 1$ & $9 \pm 1$ \\
\hline IL-5 & $23 \pm 12$ & $193 \pm 23 *$ \\
\hline IL-6 & $184 \pm 17$ & $2217 \pm 54^{*}$ \\
\hline IL-7 & $16 \pm 4$ & $26 \pm 5$ \\
\hline IL-9 & $339 \pm 43$ & $246 \pm 37$ \\
\hline IL-12(p40) & $98 \pm 21$ & $93 \pm 14$ \\
\hline $\mathrm{IL}-12(\mathrm{p} 70)$ & $29 \pm 16$ & $39 \pm 4$ \\
\hline IL-13 & $15 \pm 11$ & $168 \pm 20 *$ \\
\hline IL-15 & $7 \pm 4$ & $33 \pm 4 *$ \\
\hline IL-17 & $10 \pm 3$ & $44 \pm 4^{*}$ \\
\hline IP-10 & $93 \pm 11$ & $6177 \pm 2355$ \\
\hline MIP-2 & $18 \pm 13$ & $921 \pm 137^{*}$ \\
\hline $\mathrm{KC}$ & $67 \pm 13$ & $1983 \pm 339^{*}$ \\
\hline LIF & $2 \pm 0$ & $172 \pm 21 *$ \\
\hline LIX & $177 \pm 31$ & $262 \pm 15$ \\
\hline MCP-1 & $84 \pm 16$ & $2113 \pm 184^{*}$ \\
\hline MIP- $1 \alpha$ & $30 \pm 7$ & $460 \pm 74 *$ \\
\hline MIP- $1 \beta$ & $2 \pm 0$ & $560 \pm 122 *$ \\
\hline MIG & $669 \pm 6$ & $\mathrm{OOR}^{b, *}$ \\
\hline RANTES & $74 \pm 7$ & $281 \pm 21 *$ \\
\hline TNF- $\alpha$ & $3 \pm 1$ & $106 \pm 15 *$ \\
\hline VEGF & $34 \pm 10$ & $56 \pm 9$ \\
\hline
\end{tabular}

$a_{10 \mu \mathrm{g} \text { OVA and } 10^{7} \mathrm{GE} \mathrm{VRP.}}$

${ }^{b}$ Out of range $(10,000 \mathrm{pg} / \mathrm{ml}$ used for calculation of significance)

* Levels are significantly affected by VRP $(\mathrm{p}<0.05)$ 